\title{
Vom Wert des Flüchtigen
}

Wenn ich diese Kolumne verfasse weiß ich nicht nur, dass sie zahlreiche Menschen lesen werden. Ich weiß auch, dass ich nicht wissen kann, wer genau sie lesen wird - oder anders herum: Ich muss damit rechnen, dass sie jeder Mensch lesen könnte. Auch Menschen, die mich nicht kennen, meine Äußerungen nicht in den Gesamtkontext einordnen können oder einordnen werden, vielleicht sogar Sätze oder Gedanken aus dem Zusammenhang reißen.

Daher werde ich mich besonders um Unmissverständlichkeit bemühen, um die korrekte Verwendung von Begriffen und die Klarheit meiner Überlegungen. Das muss nicht gelingen - aber vor der Veröffentlichung werde ich überzeugt sein, dass ich es nicht klarer und unmissverständlicher schreiben konnte. Umgekehrt wird jeder Leser genau das wissen. Und mir daher jeden Satz und jede Äußerung auch zurechnen. Einmal in der Welt lässt sich ein solcherart veröffentlichter Gedanke nicht mehr zurücknehmen. Das ist auch bedeutsam, denn erst diese Ernsthaftigkeit verleiht ihm das nötige Gewicht.

Daneben (besser: davor und dahinter) gibt es aber auch das nicht-öffentliche, gesprochene Wort: Dem kann dieses Gewicht nicht beigemessen werden. Und darf es nicht. Es muss zurücknehmbar bleiben, vorläufig und flüchtig. Dieser Schutz vor unerwarteter oder unerwünschter Kenntnisnahme durch Dritte ist essentiell: Denn wir benötigen den Raum des Vorläufigen und Flüchtigen, damit Gedanken und Überzeugungen reifen können - im Diskurs, als noch zu bearbeitende Rohfassung, oder auch als zu korrigierende Fehleinschätzung oder Irrtum. Der öffentliche Umgang mit privaten Äußerungen von Politikern, die hinsichtlich aller ihrer Äußerungen natürlich unter besonderer Beobachtung und in einer besonderen Verantwortung stehen, macht manchmal vergessen, wie bedeutsam diese Flüchtigkeit für eine freie Gesellschaft ist.

Wer daher - wie ein Sprecher des Bundesinnenministeriums und einige Innenminister der Länder - den Zugriff der Ermittlungsbehörden auf die Daten von Sprachassistenten fordert, hat nicht nur den Datenschutz und die Unverletzlichkeit der Wohnung, sondern auch das Fundament einer freiheitlichen Ordnung nicht verstanden.

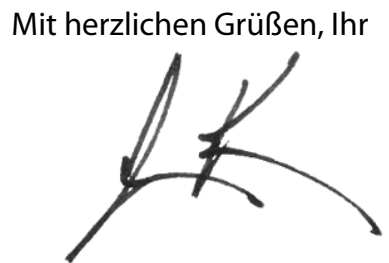

\section{Dirk Fox}

